\title{
Implementation of Music Therapy at a Norwegian Children's Hospital: A Focused Ethnographic Study
}

\author{
Fredrik Berntsen Due ${ }^{1 *}$, Claire Ghetti $^{2}$ \\ 1 Norway \\ 2 Grieg Academy - Dept. of music, University of Bergen, Norway \\ *fredrikberntsendue@gmail.com
}

Received: 20 December 2017 ; Accepted: 9 June 2018 ; Published: 1 July 2018

Editor: Rika Ikuno Reviewers: Alison Ledger, Ilan Sanfi

\begin{abstract}
The profession of music therapy is experiencing a period of expansion in Norway, with the establishment of new positions occurring in a variety of health contexts. One area that is poised for continued growth is music therapy within medical contexts, and in paediatric hospitals, in particular. There are various ways in which new music therapy positions are developed within paediatric hospitals, and studying these implementation processes can provide valuable insight. In this study, we use a focused ethnographic approach to explore how different members of the interdisciplinary team experience the implementation of music therapy in a children's hospital, including the present and the former music therapist. We consider how the music therapist has positioned herself within the established hierarchy, what leadership and other healthcare personnel have done for/against this new profession, and which elements have helped or hindered the process of implementation. Data collection and analysis consisted of reflecting upon and analysing: 1) the first author's participation in music therapy praxis on a paediatric medical unit, 2) fieldnotes from field observations within the children's hospital, and 3) semi-structured interviews with interdisciplinary staff. Main findings suggest that given support from leadership and a consultative/advisory workgroup, it was rather straightforward to start up a music therapy practice within this particular children's hospital, but it was more complicated to formally and informally fully integrate music therapy in the interdisciplinary team.
\end{abstract}

Keywords: Music therapy, implementation, focused ethnography, organizational theory

\section{Introduction}

\section{Background}

Trygve Aasgaard became the first music therapist to work in a children's hospital in Norway when he established music therapy at Oslo University Hospital in 1995 (Aeroe \& Aasgaard, 2011). With influences from social anthropology and sociology, Aasgaard's approach was characterized by valuing music therapy as a form of environmental therapy that enables interplay between children in the hospital and the hospi- 
tal environment itself (Aasgaard, 2002). A small, but resourceful group of Norwegian music therapists continues to build upon his foundational work in this area, but music therapy is far from being systematically implemented within the context of Norwegian hospitals. Though no official record exists, there are at least 10 music therapists who work in paediatric medical hospitals in Norway, and who are members of the "music therapy in paediatrics network" (Nettverket MiPE - musikkterapi i pediatri) (J. Mangersnes, personal communication, October 14, 2017). Workload percentages for the positions vary, and they are either paid for by grant or philanthropic funding or less often by the hospitals themselves.

In Norway, music therapy is clearly recommended as a treatment alternative in the national guidelines for the treatment of psychosis published by the Norwegian Directorate of Health (Helsedirektoratet, 2013). Music therapy is not specifically recommended in any of the general national guidelines for hospitalized children, though in early 2016 it was mentioned in the national guidelines for palliative care for children and youth (Helsedirektoratet, 2016). Within these guidelines, music therapy is mentioned as part of the general recommendation to provide symptom relief with a holistic focus, and in particular the guidelines state that a music therapist can make a valuable contribution to diversion and relaxation for children receiving palliative care (Helsedirektoratet, 2016). Justification for this conclusion is based on a Cochrane systematic review that supports the use of music therapy to improve children's quality of life during end-of-life care (Bradt \& Dileo, 2010). By law, all children in Norwegian hospitals have the right to be activated and educated during their hospitalization (Pasient- og brukerrettighetsloven, 1999; Sosial- og helsedirektoratet, 2016). Music therapy can be implemented as a supplement for activation and education of hospitalized children, and is recommended as part of holistic treatment of symptoms within palliative care.

\section{Literature}

The implementation of music therapy services in various settings has been studied to a modest degree, for example, music therapy services within a paediatric setting (Ledger, 2010), music therapy for residents with dementia (Suter, Elalem, Eisenson, White, \& Yanamadala, 2015), and music therapy in operating theatres (Palmer, Lane, \& Mayo, 2015). Exploration of the implementation and development of music therapy services in paediatric settings is sparse.

Ledger (2010) provides one of the most comprehensive studies of implementation of music therapy in paediatric settings. She used ethnographic research to explore music therapists' experiences of developing services in healthcare organizations, and she found field work to be a helpful way to become familiarised with hospital culture, identify key staff members, and observe the music therapist's interactions with other staff members (Ledger, 2010). The importance of identifying key staff members, or gatekeepers, was a key finding of her research (Ledger, Edwards, \& Morley, 2013).

Gatekeepers are staff members who are trusted or respected by the rest of the staff, could be either leaders/managers or nurses, and advocate for music therapy by, for example, helping gain access to patients or by allocating funding. The importance of gatekeepers was a key theme present throughout the 11 narratives Ledger et al. (2013) collected from music therapists who had developed new services in healthcare settings. All 11 music therapists experienced the implementation of music therapy as challenging, often because other professionals were resistant and protective of their patients. Risk of increasing the work load for other professionals, and the hospital's and staff's readiness for change, were also identified as important aspects to consider when implementing a new profession (Ledger et al., 2013).

Introducing a new profession within an interdisciplinary team may lead to confusion of roles (Mangersnes, 2012). Some staff members may not know what this change will bring and what role the music therapist is going to have; for example, providing music therapy for patients and parents in the waiting room, or providing psychosocial support for patients in isolation (Edwards, 2005). When such staff lack a clear understand- 
ing of the role of the music therapist, they might see the music therapist purely as an entertainer, even when the music therapist works with therapeutic goals and is also conducting a research project at the same time (Aeroe \& Aasgaard, 2011; Aasgaard, 2004). For an outsider, a music therapist can seemingly have many different roles, exemplified by the range of nicknames that patients, parents and staff members have given music therapists, such as music lady, entertainer, and teacher (Mangersnes, 2012). Some music therapists report having undefined roles in the paediatric context, with lack of formal structures such as position descriptions (Mangersnes, 2012). Full-time music therapist positions in Norwegian children's hospitals tend to have organized formal structures, in comparison with part-time positions where organized formal structures tends to be lacking (Aeroe, 2016). When full-time positions are found, they are often associated with higher levels of support and enthusiasm from leadership.

There is a small, but important, body of research exploring organizational structures surrounding music therapist positions in the field of paediatrics, but those studies (Ledger, 2010; Mangersnes, 2012; Aeroe, 2016), tend to explore the phenomenon on a broad level across several positions or settings. Ledger (2010) was the only one of these to conduct an ethnographic study, in addition to collecting music therapists' narratives. Aeroe (2016) interviewed both music therapists and their leaders, while Mangersnes (2012) interviewed only music therapists. There is a need for an in-depth exploration of the implementation of music therapy within the Norwegian paediatric hospital context, with a particular focus on organizational aspects that impact that process of implementation, as seen from a variety of interdisciplinary perspectives.

\section{Theoretical foundation}

The concept of implementation refers to the process of putting something into action, and seeking its fulfilment (Kunnskapsforlaget, 2017), and in the present case, introducing a profession within a new context. Implementation is seen as a team sport, where personal sacrifices have to be made, and problems arise when some feel committed to the implementation process but others do not (Weiner, 2009).

To understand how implementation is experienced in an organization, we have chosen organizational theory as the theoretical foundation in this article. Within organizational theory, an organization may be defined as a social system that is put together to execute specific assignments, realize specific goals, or to make one or several products (Askeland, 2013; Busch, Dehlin, \& Vanebo, 2010; Eriksson-Zetterquist, Kalling, Styhre, \& Woll, 2014; Jacobsen \& Thorsvik, 2013). In the medical context, the social system consists of all the staff members at the hospital, whereas the assignments, goals, and products are related to the treatment of patients. Furthermore, the individual hospital unit is an organization within the children's hospital, which itself may be an organization within a larger general hospital.

Organizational theory is helpful to understand and explain how organizations work, and how they change over time. As articulated by organizational theorists coming from a Nordic context, organizational theory can be understood within 5 pairs of categories; formal structure - informal structure; stability - change; organization - human; rationality - irrationality; and, man - woman (Eriksson-Zetterquist et al., 2014). Formal and informal structures include description of position, organizational culture and hierarchy, and leadership. Stability and change refers to the demand of the organization services, and how the organization changes over time. Organization and human describes that an organization is something more than a collection of individuals; they must work and cooperate. Rationality and irrationality is more of a complex category, as it is related to concepts like illegitimacy, standardising, control, routines and clarity, and it represents that one action can be rational for some parts of the organization, but at the same time irrational for other parts of the organization. In more philosophical terms, rationality and non-rationality are related to what is considered as sensible, reasonable or logical (Kunnskapsforlaget, 2017). Lastly, man and woman, is about the relation be- 
tween men and women and their stereotypes, and how issues related to gender manifest within an organization.

Several questions with relevance to the current study emerged in light of this theoretical foundation, for example: how is the music therapist's position organized within the hospital (Mangersnes, 2012); where in the hierarchy does the music therapist belong (Aeroe, 2016); has the staff experienced any change; are there any individuals that have worked as gatekeepers (Ledger et al., 2013); what facilitating factors have been helpful; and, is there any difference between men and women in this setting? The five organizational theory categories mentioned above are helpful when discussing the aim of this study.

\section{Research aim}

The aim of this study was to explore how different professionals have experienced the implementation of music therapy at a children's hospital in Norway. Our primary research question has been:

How is the implementation of music therapy experienced at a children's hospital? With three secondary research questions:

What has the music therapist done to fit in the established hierarchy?

What have other healthcare personnel and the leadership done for/against this new profession?

What elements have helped or hindered the implementation?

\section{Method}

\section{Study overview}

This study was conducted during the autumn of 2016, at a children's hospital housed within a larger university hospital in Norway. We used focused ethnography employing triangulation of data sources, which included the first author's praxis in a similar paediatric medical setting, field observation and semi-structured interviews. The aim of the study was to explore how the implementation of music therapy in a paediatric hospital is experienced by key interdisciplinary staff members and the music therapist herself.

\section{Focused Ethnography}

In contrast to traditional forms of ethnography, in which long-term immersion in the setting of study is a necessity (Emerson, Fretz, \& Shaw, 2007), the focused ethnographic approach can accommodate shorter periods in the field, with a narrower focus on particular elements of the setting (Knoblauch, 2005). Like traditional ethnography, focused ethnography is not field specific, as it has been meaningfully applied in different fields, for example NICU culture of care for infants with neonatal abstinence (Nelson, 2014), and health and social care needs of Somali refugees with visual impairment (Higginbottom, Rivers, \& Story, 2014). In our study, we focused on the implementation of music therapy services related to one job position, and interviewed selected professionals who came into regular contact with the music therapist.

Focused ethnography requires that the researcher has knowledge about the milieu he or she is entering (Knoblauch, 2005). The second author has experience with developing a music therapy position and offering in a children's hospital within a large teaching hospital, and initiating music therapy services on adult medical units. The second author also has extensive practical experience working with children, adolescents and adults in medical settings. Since the first author had not worked in a medical context earlier, it was necessary to gain first-hand knowledge about this setting. The first author sought out the opportunity to complete an independent music therapy praxis at a different paediatric unit in the same hospital. The praxis, a part of the 
educational program at the university, marks the last praxis period of the education. Students are challenged to function as independent music therapists for a given period, and receive supervision externally from the study program. The first author provided music therapy at this unit 2 days per week, September 2016 to January 2017, while the second author provided external supervision. Praxis was conducted at this particular unit, which is both administratively and physically separate from the children's hospital, so as to avoid influencing the process of implementation within the children's hospital that served as the field of study.

\section{Data collection}

The following sections describe all aspects of study preparation and data collection. We used triangulation of data sources in order to explore consistency between sources and enable a more comprehensive understanding of the phenomenon (Patton, 1999). Data sources included self-experience from participation in praxis on a paediatric medical unit, participant observation and fieldnotes, and semi-structured interviews.

\section{Praxis}

$\mathrm{I}^{1}$ completed praxis at a separate paediatric unit, to become familiar with the medical paediatric context. I did not collect any data from the praxis period that has been included in this article, but during the praxis, I wrote a personal journal with memos of music therapy sessions I had with patients, and situations that happened on the unit, all adequately anonymized. I also completed a set of reflection assignments about my time at the unit, which were part of a compulsory subject within the music therapy educational program. The time I spent at that particular unit, together with the memos and reflection assignments, impacted my preunderstandings, so that I had some knowledge about providing music therapy in a medical setting and on a paediatric unit, and the associated interpersonal dynamics with staff and families, before I started my observation period. For example, through praxis I learned how nurses work, how they are organized during the day, and how they collaborate with doctors and head nurses. I learned how to negotiate my position within the daily activities on the unit, and how to resolve conflicts that arise in the process of implementing a new offer of music therapy. This experience of praxis might have influenced how I reflected upon the data during the research process, and how I generated themes during the analysis process. I tried to reflect carefully upon how my participants' experiences might have varied from my own, in order to remain open to their unique experiences.

\section{Observation and fieldnotes}

Observations at the children's hospital were completed over an 8-day period, where the first half was spent shadowing the music therapist, and the second half was used for interviews. Shadowing the music therapist, I was both a participating and a nonparticipating observer, whichever felt most natural in the moment, if either the music therapist or a child invited me to join in on their musical interaction. This flexible approach was agreed upon with the music therapist prior to shadowing.

I took fieldnotes every day, whenever it was necessary and I had the opportunity. I tried to be as discreet as possible when taking notes in a small, pocket-sized book, so that the people the music therapist and I interacted with during each day would not feel observed and analysed. During the observation time, I jotted down keywords and quotes, so that in the evenings, I could use my fieldnotes to write a continuous full text (Emerson et al., 2007). It was important to do this during the first half of my days in the field, so that any emerging themes or situations could be explored further during the interviews. 


\section{Semi-structured interview}

In the second half of my observation period, I completed the semi-structured interviews. I used a chain-referral method, snowball-sampling, to recruit participants (Cohen \& Arieli, 2011). The leadership decided amongst themselves who I was going to interview within the leadership. I started by interviewing this selected leader, who thereafter identified two nurses who could be rich sources to interview. It was necessary to interview the current music therapist since she was the only one on the unit, but she also suggested a doctor and a previous music therapist to interview. Participation in the interviews was voluntary, and a total of six individuals consented to being interviewed as part of the study.

I used semi-structured interviews to elicit the interviewees' own descriptions of the phenomena that they experience throughout their work at the unit (Kvale \& Brinkmann, 2015). I followed an interview guide that contained mainly open-ended questions, which made it possible to ask follow-up questions and engage in a form of dialogue with the participants. Interviews were conducted in Norwegian, to reflect the native language of the participants. The interview guide included questions relating to: which aspects related to implementation of music therapy have been difficult and/or easy; how participants have been involved in the process of implementing music therapy; which aspects have facilitated or hindered the implementation of music therapy, how does the music therapist experience her/his identity within the medical system, etc. The interviews lasted from 20 to 90 minutes, and I audio recorded all of them using a ZOOM H1 handy recorder. It was not necessary to have follow-up interviews with the participants, as I found their descriptions sufficient to achieve the study's research aims. However, I did send an email to the music therapist with four short follow-up questions to seek clarification of a few details stemming from the interview. After I had decided which quotes I wanted to use in the findings section, I sent an email to the former music therapist and the interviewed leader, with their respective quotes. Both of them were satisified with the quotations, and neither had any comments about wording or contents. I decided not to send quotations to the other interviewees, since their quotations were not as sensitive in nature.

\section{Data analysis}

Analysing data is meticulous work, and it required using different methods in order to describe the data in the most comprehensive way. I analysed the interviews and fieldnotes using a combination of two qualitative methods: "meningskonsentrering [meaning condensation]" (Kvale \& Brinkmann, 2015) and "systematisk tekstkondensering [systematic text condensation]" (Malterud, 2011). I consulted with the second author to develop a plan for data analysis, and we maintained reflective dialogue as my process of data analysis unfolded.

I started by listening to the audio recordings, and transcribing the interviews word by word. Although the interviewees' dialects were quite different from my own, I felt that I had sufficient enough understanding of their dialects to enable direct transcription into Norwegian bokmål ${ }^{2}$, which subsequently made it easier to read and analyse further (Kvale \& Brinkmann, 2015). Fieldnotes were at this point complete texts, and did not require any more transcribing.

I continued by reading the transcriptions and fieldnotes, and drafting in pencil in the margins the themes and categories that began to emerge inductively. This process helped me get a general impression and seek out fragments of significance (Malterud, 2011). A tremendous number of potential themes and categories emerged when just taking notes by hand, and I realized I needed to further organize my analysing. I decided to first condense all my interview transcriptions into more concise writing, to make them easier to work with (Malterud, 2011). A total of 123 pages of transcriptions were condensed down to just 30 pages. Secondly, in order to further organize the analysis process in the most useful way, I used the qualitative data analysis software NVivo, and did a new inductive analysis of the condensed transcriptions and fieldnotes, mak- 
ing codes as they emerged chronologically. After the first attempt in NVivo, I made a rough draft of the results in a text editing software, which allowed me to combine some of the themes that were similar.

While completing these steps, I became aware that categories from my theoretical foundation in the organizational theory literature were present in my mind, and influencing how I was inductively forming categories in the data. These were "implementation" and the five categories from organizational theory (Eriksson-Zetterquist et al., 2014). At the same time, other new themes beyond these categories emerged and necessitated the formation of additional categories.

I analysed the data a final time, again using NVivo, but this time creating the codes before I read through and then coded the text deductively. The codes the last time were the five organizational theory concepts, along with "implementation", as main nodes, with the themes from the first NVivo analysis serving as sub-codes. Again, I made a rough draft of the results in a text editing software, and combined it with the first draft. These two drafts served as a type of template for the results section.

\section{Ethical aspects}

The study followed ethical standards for conducting research in Norway, including receiving approval from NSD - Norwegian Centre for Research Data, for the appropriate handling of personal data. Written informed consent was obtained for those participating in interviews, and verbal consent was obtained for participant observation without collection of personal information. The participating children's hospital approved procedures used in the study, and the first author signed and abided by the hospital's own declaration of confidentiality.

Staff members who were interviewed were identified by a single letter; A, B, C, etc., before data analysis. In the fieldnotes the staff members were given a title only. No patients were described by age, gender or current health situation in the interviews or the fieldnotes.

Due to the relatively small sample of interviewees coming from the same children's hospital, it is impossible to completely anonymize all the interviewees so that staff from that particular hospital will not be able to identify the participants. To counter this limitation, we attempted to adequately anonymize interviewees by not stating any names, ages, or their actual job titles, and by presenting them all as female. Furthermore, since I sent the quotations to participants for whom I deemed it nessesary (those whose identity could be inferred from their job position, for example), and none of them had comments, I felt it woud be appropriate to include these quotations in the article.

\section{Findings}

We present data from the six interviews and fieldnotes, organized into three sections according to key concepts from organizational theory. Two of the headings, formal structure/informal structure and stability/change, originate from the five organizational theory concepts put forth by Eriksson-Zetterquist et al. (2014), and the third heading, facilitating factors, was created in the current study to encompass themes related to elements that aided the process of implementation. Each section includes sub-headings that reflect a pairing of concepts from organizational theory with categories that have emerged inductively from the analysis. Two of Eriksson-Zetterquist et al.'s (2014) organizational theory concepts, rational/non-rational and organizational/human, were used to assist critical reflection upon the results within the discussion section, while their final concept, man and woman, was not included, as it did not clearly link to any themes that emerged from the analysis. All quotes from the interviews have been translated in the most literal way possible from the transcriptions, in order to preserve the interviewees' original language and expression. 


\section{Formal structure and informal structure}

Formal structures and informal structures can be seen throughout the organizational structure of the children's hospital, and manifest in specific areas of structure and leadership, organizational culture, location, and the process of generating referrals. Structure and leadership, and organizational culture and hierarchy were categories that informed the deductive analysis, whereas the categories of location, and formal referrals and informal requests, emerged during the inductive analysis.

\section{Structure and leadership}

Initiating a new music therapist position can involve a lot of different people and structures, which was true in this particular case. The following describes the various aspects of structure and leadership that support the current music therapy position, in contrast to previous part-time music therapy positions within the same organization.

The previous music therapist described the short history of music therapy at the hospital, as follows: there have been at least two music therapists engaged in part-time positions previously, and those positions were organized in different ways and supported by external funding. Three years prior to the current music therapy position, external funders funded a full-time music therapy position for the overall hospital, with $50 \%$ time allocated to the psychiatric hospital for children and youth, and $50 \%$ to the paediatric medical units. Within the medical side of this position, the music therapist was challenged to cover four different paediatric units. During the summer of 2015, the psychiatric hospital took responsibility for funding a full-time music therapy position, which that previous music therapist received. Around the same time, the university's music therapy program and other departments of the hospital partnered with the previous external funders to create a 3-year, full-time music therapist position for the medical units, which started in January 2016.

This new project was at the time administered by the children's hospital, and served children that were admitted to the children's hospital. The project had both a steering group and a working group, consisting of members from all involved funders and partners. A project plan was developed for the new position, with an aim to build a solid, research-related music therapy offering that is included as part of the children's hospital treatment offerings ${ }^{3}$. The plan stated that music therapy should be developed as an integrated and natural part of assessment, treatment and follow-up for children and youth across both medical and psychiatric services. At the children's hospital, the music therapist was at the time formally organized under one of the units, and this unit's leader was the music therapist's direct supervisor. The music therapist could also follow patients on other units within the children's hospital, and nurses and doctors on those units could refer patients to the music therapist.

Having just finished the first year of the three-year period, the leadership decided to formally hire the music therapist. This decision did not indicate a rejection of the funding, but instead meant that the music therapist was assured continued employment after the project period. The music therapist described this decision as being a brave one:

I think it was brave of them actually, because they had been really clear that they didn't want to give me a position, at least not that quick .... It is at the expense of other things, that they have to give less priority.

The music therapist further described how her first ten months at the children's hospital had been structured. She had been free to do what she needed to in order to become acquainted with the unit and the children's hospital. She herself decided which patients to visit and what kind of music therapy to offer them:

I haven't been given any directions ... instructions on how it should be, or how they imaged it to be, but I don't think they have completely known either ... you have to try it out before you can find a direction, now I suppose we have come to a point where we need to find a direction. 
The music therapist was given a lot of independence, with freedom to choose her course in what to do, and what not to do regarding music therapy, as the leader described:

... she's been here almost a year, and has kind of used most of the time to learn the health system, gotten to know the health system, that has anyway been our intention, because you need it, to understand the difference between one thing and another, and to learn the culture, learn about all of the professions, learn how we work, ... so that the music therapist that is here now, has in a way not been that guided, no, but that has also been intentional.

The music therapist had been given ample independence in striking a course for the implementation of music therapy services, but certain institutional structures have interjected in this process, the most prominent being practices surrounding receiving referrals.

\section{Formal referrals and informal requests}

As a part of the formal structure related to the current music therapy position, a template for formal referrals was available within the hospital's patient journal system. The previous music therapist created it on her own initiative, to streamline the processes of informing other staff members about music therapy and seeking out appropriate patients for services. At the time of the study, the formal referral template could be used by both nurses and doctors to refer patients to music therapy, or to add music therapy to a patient's formal treatment plan. Despite the presence of a formal referral system, the leader stated that only a few formal referrals (approximately one per week) had been made to music therapy. She felt that the number of referrals could be viewed as a preliminary quality indicator that demonstrated how well music therapy was being implemented. The nurses acknowledged this function, as nurse A described:

[the leadership] understands the value [of music therapy] ... that we should refer to music therapy, because that is kind of more formal and proper, ... so that it becomes a part of the treatment team ... so that it's not simply one that comes to sing a little bit.

In contrast, informal requests for music therapy were made several times every day, verbally passed on at morning meetings or when the nurses/doctors and the music therapist randomly met each other on the unit. The morning meeting consisted of one of the nurses, the music therapist, the play therapists and sometimes the clowns, going through the list of patients that were on the unit that day. The leader was aware that many informal requests were being made in this manner, but said:

That is not how we want it ... if you wish it to be part of something...it would be that referrals for music therapy were made in the same way as referrals for physiotherapy, for occupational therapy, for psychology, for, yes, for all professions. Then I would feel that it was implemented.

Other professionals received formal referrals through the journal system, and those services were part of a patient's formal treatment plan. At the time of the interviews, such procedures were not yet functional for music therapy, the leader described.

The categories of structure and leadership, and referrals and requests, represent formal structures associated with the music therapy position. The next category, location, could also be viewed as a structure, with a physical manifestation. The children's hospital consists of rooms, corridors and furniture that provide the formal structures, but they may also be used informally in ways other than originally intended.

\section{Location}

Locations can be viewed both as formal and informal, where formal structures consist of the rooms and spaces provided by the hospital to serve a certain purpose, for example walking and transporting patients in the corridors, eating in the dining room, 
and conversations in the consultation room. The informal locations reflect the use of these same rooms and spaces in a way that corresponds with direct need as opposed to original intent, as later described.

During 2016, the children's hospital moved from its old and outdated building into a new and modern one, serving as a temporary location while the old location was being torn down, and the new permanent facility built. This new building smelled and looked new and modern, all walls were white, with sparse or no decoration. At the unit, one immediately encountered the unit's reception, a waist-high counter, with glass windows all the way up to the ceiling. Through the windows, one caught a glimpse of the nurses' closed office space. Through huge doors on either side of the reception, corridors lead to the patient rooms, consultation rooms, and storage. Almost all of the patient rooms were single patient rooms, also with sparse decoration. There were no sitting areas with sofas in the corridors or beside the nurses' office, but there was an available sitting area within the unit's dining room.

Since this new location served as a temporary and somewhat generic space for medical units (not specifically or exclusively designed for paediatric use), it was not designed to accommodate the needs of the music therapist. The music therapist shared a cramped office together with the play therapists, and her musical instruments and trolley had to be stored in a common storage room. The old music room was now located too far away to be used. Losing the music room not only influenced the type of music therapy offering that patients received, but it also impacted the music therapist's own musical development, in a way that she described as:

... negatively as I've lost my office, and, music room, so I don't have my own office any more, and I don't have a place to bring patients, or to practice. The practice part has gotten a lot less, and that is needed for my own sake since I've changed field, and must practice on different things than before. I don't have a practice room, [the storage room] is the only room I have, I sit there now and then, in lack of other places to go.

Lacking space for practicing reduced the music therapist's ability to prepare for sessions and practice her own musical skills. This negatively impacted the musical aspect of the music therapy that she was offering. The music therapist sometimes used the unit's consultation rooms, both as a practice room and a place to have sessions with patients. She felt that such informal use was not ideal, as these rooms should be available for timely conversations between nurses/doctors and patients/parents.

The lack of spontaneous open music therapy sessions in this new location impacted the nurses as well, who perceived the new unit as being too formal in a way. Both the nurses and the music therapist missed informal sitting areas in the corridors, as one of the nurses described that the old location had groups of sofas in the corridors. Here the nurses could easily join the music therapy sessions that happened spontaneously there. Nurse B described:

... I think it's become a little less personal ... we feel as if we are a little more on the outside, it becomes harder for us to come across [the music therapy] ... in the corridor, right, and we could join in on the music when the music therapist was there with everyone, and they sang and played. We feel a lot more shielded in here, in comparison to where we were before.

Being on the outside, was something that nurse A also described, while she compared the nurses' office space to a bunker: " ... It was much easier to just sit down in the corridor ... now we sit too much in that bunker of ours, and almost haven't got a clue about what's going on in the corridor."

Separation from the unit itself with a more closed office space made the nurses feel like they did not see the music therapist as much as they did before. In contrast, the music therapist felt that she saw the nurses more, since she knew where to find them in their offices:

...it's easier to sit down and talk with [the nurses] than before, because they have their staff rooms and their own computer rooms ... I think that they maybe have become a lit- 
tle more isolated from the hospital, that they now have their staff room, ... but regarding talking with them, it is much easier here.

The nurses were in number the largest staff group, and the staff group that had most connection with the patients, and, they were also most often the first staff members that the music therapist consulted with before visiting a patient.

\section{Organizational culture and hierarchy}

The leader emphasized that when starting in a new position at a new place, one needs to learn how the culture and the hierarchy within the organization are formed. While the more formal aspects of culture and hierarchy were described in the structure and leadership section, this section will focus on the informal aspects, how organizational culture and hierarchy were experienced subjectively.

As previously mentioned, the music therapist was given time to get to know the culture within the children's hospital, which included getting to know the people within the culture. When asked who she communicated with, the music therapist stated:

Yes, everyone ... it just goes that way ... but I am a bit of an outsider, and a bit across, both in units and floors ...but maybe those who I feel I belong to are the nurses after all ... I do admire the work that they do, and if anyone's got to go, it's me who has to go first. Nobody dies from not having the music therapist there.

The music therapist appeared to feel that the nurses played a more crucial role than she did, but she also felt a form of alignment with nursing. She mentioned that she perceived it to be a slight weakness that she did not have any form of medical competence, and thought a rudimentary course in medicine would be helpful.

Although the music therapist felt that she was generally on the same level as the nurses in terms of institutional hierarchy, there was a difference between what she subjectively felt, and what others within that hierarchy perceived. The leader described it like this:

Music therapy as therapy would need a relatively long time to come on the same level as others who see themselves as part of the treatment team for the patients. That is because of the hospital's hierarchy, and a culture, which, yes, is old. Music therapy is relatively new ... and within the hospital it is probably even newer, so I think that a new profession would use time to come on the level that they should be.

In relation to the music therapist's positioning within the established hospital hierarchy, there had been some disagreement regarding how extensive the music therapist's involvement should be. For example, some staff members had questioned why the music therapist attended some of the meetings where patients were discussed, due to the level of sensitive information shared within those meetings. They wondered if the music therapist should have access to confidential information about every patient or not, or have access to doctors' notes. Both the previous and the current music therapist did not have access to doctors' notes in the journal system, which in some cases led to the music therapists missing information pertinent to the patients they had seen. The leader articulated this potential reluctance to give the music therapist comprehensive access by saying that not all the nurses know everything about all patients.

Divisions within organizational culture may also be reflected in simple structures such as the kinds and colours of uniforms worn by various types of staff. The nurses, as the employee group of greatest number, wore white uniforms, as did the doctors, cleaners, and orderlies. Some of the nurses and doctors also wore green uniforms, depending on which part of the overall hospital they belonged to, for example anaesthetic nurses and surgeons. The play therapists, physiotherapist and music therapist all wore blue uniforms. The current music therapist did not get to choose whether or not to wear a blue uniform or private clothes, and she felt that wearing a blue uniform may have impacted some of the clients, as she described: 
... the adolescents are difficult to reach, I have tried to find a way to get their approval, and maybe via something other than music too ... But many have been very uninterested ... it might be because of me and my inexperience... [could it be because you wear a uniform?] ... maybe, I don't know, that might be one of the reasons ... their experience of me... they might view me as a very hospital person.

The music therapist's position within the hospital hierarchy was influenced by both formal and informal aspects, as described above. Some formal aspects such as full-time employment and job description can be considered as stable elements, while informal aspects such as one's subjectively perceived position in the hierarchy can change over time.

\section{Stability and change}

The descriptions of structure, referrals, location, and organizational culture mentioned above all relate to the category of stability and change, as all of them are stable or unstable, where unstable refers to being in a state of flux. Structure and leadership, and locations were stable at the time of the interviews, while the remaining, referrals and requests, and culture and hierarchy were unstable structures. Following are descriptions of these unstable structures.

In the leader's view, the demand for music therapy needed to increase in order for it to be fully implemented within the formal hospital system. The leader felt that currently (at the time of the study):

[Music therapy] is implemented in a way that it is entertainment, and it is implemented in a way that the music therapist comes every day and, together with the play therapist, right, comes and sees which patients are here today, and then the music therapist ... can visit single patients, but, I don't see that the number of referrals has increased.

In the leader's perspective, music therapy as entertainment was implemented in a stable manner at the children's hospital, with informal requests being made regularly, but music therapy as therapy, was at the time a rather unstable offering. The leader emphasised that the number of formal referrals had to increase for music therapy to come closer to being implemented as music therapy.

The leader stated that everyone can appreciate music entertainment, since it is fun and nice, and therefore easier to implement than music therapy. None of the doctors had included the current music therapist in a formal treatment plan at the time, which was a culture that the leader felt needed to change:

... it doesn't work like that someone necessarily can decide it, because it is the larger professions who must consider, ... do we want to include a music therapist in our team, or are we aware that we have the possibility to make a choice to have a music therapist here.

The leader's sentiment was that no single person could mandate that music therapy be integrated as a therapy alongside all the other professions within the unit. A collective change of mind is needed, which is something that takes time.

Certain key individuals in leadership had contributed to the music therapist's sense of stability during the process of implementation. The music therapist had expected it to be harder to start up her practice, but she felt that it had helped that the head of the children's hospital had been positive and affirming towards the staff, as she described:

... I didn't know what I was going to do, so it was all very new to me ... . I did think that I would meet more resistance from people, but people have been very positive in every section, both from the leadership and nurses.

Many staff had been positive, but the music therapist said there was still a big difference in how various nurses were thinking about music therapy, and subsequently how they were making referrals/requests. Some nurses seemed to make appropriate referrals/requests for music therapy, while others made requests based on a narrow understanding of music therapy, as the music therapist explained: “...what the children 
should be referred for, and it's not only joy and fun, or that they are bored in their room, but that there are other things too." As the music therapist became more confident in her role at the children's hospital, she could also make her own judgements as to which patients to visit or not.

Both nurses that were interviewed perceived that the leadership valued music therapy more at that time than earlier, and that they viewed music therapy as a part of the overall treatment offering. The nurses mentioned that music therapy could be used for play and fun, and in pain management for children, but also in palliative care. Nurse A said:

... when we sit in groups and discuss, [music therapy] is not always the first thing we remember, but sometimes we see that, ok, now there's one [patient] that is starting to get withdrawn, or if one goes over to a palliative stage or something, we then see that they maybe need [music therapy].

The two nurses were both positive to music therapy, but observation suggested that there was still some instability in people's general attitude toward it. The following example happened during the observation period, and was mentioned in the interviews with the nurses, the doctor and the music therapist. The music therapist had earlier joined the anaesthesia team on a few occasions, to provide procedural support to help patients relax prior to receiving sedation for minor procedures. The anaesthetic team were not a set team, and so the music therapist encountered a different set of nurses each time she joined in. On the particular occasion, the anaesthetic nurse was apparently unfamiliar with music therapy, and did not understand how music therapy could provide non-pharmacological sedation. Consequently, the anaesthetic nurse did not grant the music therapist access to the treatment room.

This last paragraph illustrates the instability of the nurses' level of knowledge about music therapy. Some nurses were not so familiar and not so keen to collaborate, while other nurses were eager and happy to join in and support the music therapist, and they understood the aims and scope of music therapy. The music therapist initially had successful collaboration with the anaesthetic team, because of two nurses whom acted as gatekeepers, a role that served a facilitating function during implementation.

\section{Facilitating factors}

Implementation is a team effort, and all of the above descriptions contribute to an understanding of processes involving implementation. It takes time to implement something new and unfamiliar, and it is not easy work, the leader stated:

I think it's important to be patient, and that it takes time, and implementation can be one thing in theory, and another thing in practice. Especially when you are going in to a hospital culture which is set during many, many, many years, so it takes time to change.

Three concepts emerged during the interviews that reflect factors that ease the long process of implementation; gatekeepers, being present and educating staff. These concepts may be thought of as facilitating factors.

\section{Gatekeepers}

The two nurses that were interviewed were chosen by the leadership to be the music therapist "gatekeepers" or "collaborating nurses" (as directly translated from the music therapist's term), though the topic of "gatekeepers" did not specifically arise in the interviews. The exception was one quote from the music therapist, which illustrated an important example of how gatekeepers' influence could be helpful to start up a small project:

...but the entire anaesthesia project started without us talking to any of the leaders ... because it was those collaborating nurses of mine that just said ... 'you can just go [to the procedure room] and join in,' yes, and I don't think that this project would have started if we had asked the leaders first. 
Though not specifically mentioned in other interviews, the gatekeepers were important in starting up this particular initiative. In a follow-up email, the music therapist also mentioned that the play therapists had been supportive, and although not directly serving as gatekeepers, had been important resources for the music therapist.

\section{Being present}

The music therapist had intentionally spent a lot of time just being present on the unit, inviting the nurses to join the music therapy sessions, and joining the nurses when appropriate. She was allowed to devote time to orienting herself in the hospital system, and educating other staff about music therapy. She was careful to use language that they would understand, and explain the scope of her aims.

The music therapist believed it would be ideal to have several music therapists working in an overlapping shift plan, like nursing, to expand access to services:

... I wish for it to be noticed when I'm not at the unit, ... that it is an offer that should be actively made use of, but I do see that it is very vulnerable, because you are alone. If we

had been many we could have been more available ... and offered more.

It is insecure for music therapy to be limited to just one employee, as there is a lack of coverage during her absences. She felt as if the process of implementation took a few steps backward every day she was not at the unit. In the busy everyday life of the unit, there was still quite a way to go until music therapy is solidly and stably implemented.

\section{Educating staff}

The current music therapist has used in-service training to educate the interdisciplinary team about music therapy. She typically described her focus (including an upcoming research project), explained music therapy goals, and demonstrated approaches. The music therapist believed that describing the specific aims of music therapy was important, since many staff still thought that music therapy was primarily for play, fun and amusement. The music therapist was proactive about talking to other interdisciplinary staff about music therapy, including at morning meetings.

\section{Discussion}

The current study explored how the implementation of music therapy is experienced at a children's hospital. The experience of implementation of music therapy differs between the various professionals who participated in this study, in relation to where one is within the hierarchy at the children's hospital. Overall, the participants in this study experienced the implementation of music therapy as a process that required change, but had a relatively straightforward start. The music therapist has been able to follow patients she assesses are appropriate for music therapy, and has regular, brief informal consultations with primary nurses. This relatively easy start was made more complex by a lack of consistent understanding of the music therapist's role, with some personnel being unsure of whether she was an entertainer or part of the formal treatment team. Informally, the music therapist is accepted as part of the treatment team, as demonstrated by her frequently receiving informal requests from the nurses. Formally, the music therapist is not regularly receiving formal referrals or being included on patients' formal treatment plans, as of the time of this study. This lack of formal integration into the treatment offering suggests there is more work to be done before music therapy is fully integrated into this system. We will now explore the main findings in light of the existing literature, and organize the discussion around two remaining categories from organizational theory (Eriksson-Zetterquist et al., 2014), rational/nonrational and organizational/human. 


\section{Referrals}

The differential role of formal referrals and informal requests has emerged as one of the most prominent themes from the results, and links to many of the other themes. Referrals and requests are clearly relevant on two different levels, as a structural concept within the organization, and as a part of other professionals' mind-set regarding stability and change.

On a structural level, participants clearly articulated that nurses in general could be better at making formal referrals for music therapy. At the time of the interview, all formal referrals came from nurses, at the rate of approximately one per week. The leadership views such referrals as an indicator of quality within the process of implementation, and a step towards achieving full integration of music therapy into the hospital system. Despite a clear rationale from leadership for the use of formal referrals, such referrals may not be a natural part of daily practices, a phenomenon that Aeroe (2016) found in other Norwegian paediatric hospitals. The music therapist informants in Aeroe's study received referrals and requests from medical or pedagogical personnel in several different ways, including hand written notes, phone calls, emails, in interdisciplinary team meetings, or via the journal system.

The generation of electronic formal referrals requires several steps. In comparison, informal requests can occur efficiently and directly during the course of morning meetings or other communication. It is understandable that nurses might find it easier and more efficient to make informal requests when they encounter the music therapist, and might feel this approach is a more rational one, though it might undermine efforts to establish a systematic practice of formal referrals. Organizational change can result in new requirements or practices that other professionals must adjust to, which could cause an increase in their workload, disruption of their routines, and surrendering of their territory (Jacobsen \& Thorsvik, 2013; Ledger et al., 2013). A collective change of mind is then clearly needed to adopt this practice in regard to this new profession (Jacobsen \& Thorsvik, 2013). If the leadership continues to view the number of formal referrals as a quality indicator of implementation, reluctance of nurses and doctors to start making formal referrals could hinder music therapy from being fully implemented as therapy.

An increase in formal referrals for music therapy might not change the given music therapy's quality, but it might change which patients receive music therapy, and why they receive it. If the music therapist only sees patients based on her direct knowledge of them, she may miss patients who could benefit from such services, if she is not well enough informed about their needs. Within this particular children's hospital, the music therapist cannot access doctors' notes. This limitation has impacted the music therapist in some cases, as she described missing important information about the patients she follows.

The music therapist in our study felt that access to the journal system is important, since it allows her to document processes and outcomes of music therapy, which helps inform other professionals. Although she has access to most parts of the journal system, other music therapists working in similar settings have different levels of access; for example, not having access at all (Aeroe, 2016), or being given a different professional title (e.g. pedagogue) in the documentation system (Mangersnes, 2012). Such variations in journal access and professional titling might result in confusion of roles, and the staff's general opinions toward music therapy might be influenced negatively. Furthermore, in Norway health professionals by law must document any health related service given to a patient (Helsepersonelloven, 1999). Since music therapy does not yet have formal authorization as a health profession in Norway, hospitals are not required to grant music therapists access to the journal system. Music therapists who are denied access to the journal system may find it challenging to maintain professional expectations in relation to documentation. 


\section{Role of the music therapist}

The participants in the study had different rational and non-rational ways of conceiving of the role of the music therapist, including how they accommodated concepts of therapy and entertainment. One of the nurses said that the leadership now sees the value of music therapy, but on the other hand, the leader herself views the current implementation of music therapy as being aligned more closely with entertainment. The nurses never used the term entertainment to describe music therapy, although aspects of the music therapy they described had elements of entertainment. The interviewees seem to be in agreement that music therapy becomes therapy when it is integrated in an interdisciplinary treatment plan, as opposed to when the music therapist seeks out her own clients. Music therapy is not currently integrated in any formal patient treatment plans, which perhaps informs the leader's perception that the amount of therapy given, vs. entertainment, is maybe $50 \%$. Thinking that music therapy should not contain any aspects of entertainment is rational when considering that the hospital wants to maximize the therapeutic offer; however, such thinking may also be non-rational, as music therapy can include aspects of entertainment at the same time and still be therapeutic (Ledger, 2010; Mangersnes, 2012; Aeroe \& Aasgaard, 2011).

This mix of the concepts of therapy and entertainment reflects very well on the complexities and contradictions of the culture at the unit. It does not seem that there is a general understanding of the music therapist's role in the interdisciplinary team, nor clear distinctions between therapy and entertainment. This might also explain why there are so few formal requests being made.

\section{Locations}

At the time of this study, the aspect of music therapy's "location" could be viewed as non-rational and unstable. When the new, temporary location was being built, music therapy was not specifically allotted space. The music therapist does not have a separate music room where she can practice her own musical skills or bring clients for music therapy. As Ledger (2010) describes, a lack of proper facilities may be tiring for music therapists, as they spend a lot of time setting up instruments in several different locations each day, and consequently have less time to complete paperwork or documentation.

The design of the hallways and corridors also hinders spontaneous music therapy sessions from happening, which previously occurred at the old location. The lack of spontaneous music therapy sessions has made it harder for nurses to engage with the music therapist and in music therapy sessions. Aasgaard (2004) made good use of the hallways and corridors within a children's hospital as a means of musicalizing the environment, and argues that music therapy sessions in these open spaces has positive effects for both patients and parents, as well as nurses and other staff members.

\section{Music therapist}

When a music therapist is offered a position, there is a great chance that he or she will be the first and only music therapist in the team (Ledger, 2010). The music therapist in this study stated: " ... you have to be unafraid to get [music therapy] implemented." The music therapist has to be confident and to defend her work, through in-service training and occasionally fielding critical questions from other professionals. Music therapists involved in implementation can face challenges related to documentation and misunderstanding of their role, and might have to seek out patients themselves (Mangersnes, 2012; Aeroe, 2016). The leader emphasized that one needs to be a "stayer," to succeed in an implementation process.

The music therapist in the study sometimes felt alone as the single one from her profession at the children's hospital. A nurse we interacted with during the observation randomly called the music therapist a "naughty child," which might be connected to her making an impact while working alone as a music therapist, or to taking 
chances while breaking into new structures and cultures, often from her own initiative. The music therapist responded to this statement by describing that she sometimes has stepped a bit over the lines, leaping into stuff, and doing things how she wanted. She acknowledges this as a necessary part of implementation, but also one that can create challenges. One individual staff member working for change might have to push a lot harder to create change than if a whole team is behind such an effort (Eriksson-Zetterquist et al., 2014). A single music therapist working in isolation will have to work a lot harder to facilitate implementation, without support from fellow staff members.

\section{Healthcare professionals}

The presence of gatekeepers has proven to be important when starting up a new position (Ledger et al., 2013). The two nurses that were interviewed were chosen by the leadership to be the music therapist's gatekeepers, or collaborating nurses. It was clear that the project with the anaesthetic team was able to start up because of the gatekeepers' influence, even though these two nurses were not in any particularly powerful positions as head nurses or the like. Ledger (2010) experienced a similar phenomenon in her ethnographic study: a gatekeeper can act with a lot of influence, even though she or he is not in a formal position of power.

When asked if they have done anything that could have helped or hindered the implementation of music therapy, both nurses were quick to state that they had not done anything to hinder it. In some aspects, this was true, as they have a generally positive attitude towards music therapy and speak supportively about it to others, they take music therapy into consideration more frequently when discussing patients, and they have acted as gatekeepers for the music therapist. Despite these facilitative steps, the leader clearly stated that the number of formal referrals made by nurses and doctors remains low. It may be that it takes too much effort to make formal referrals, or it could be that nurses remain protective of their patients and are somewhat sceptical to music therapy, as previously described within the anaesthetic team initiative and echoed within related literature (Ledger, 2010).

We included a doctor among the interviewees, but since music therapy has not been formally included yet in patient treatment plans, the music therapist has not had many interactions with this doctor, or with others. Despite a lack of regular interaction, the doctor thinks that the music therapist does her job well, and she hopes for further development of music therapy at the children's hospital.

\section{Leadership and structure}

The leadership has done several things that have helped implementation. The leadership enabled the formation of a formal supportive structure for the position, including a project leader, steering group and work group. Furthermore, the leadership committed to a permanent position for the music therapist, even before the funded 3-year project period was finished. The leadership wants to include music therapy as part of both the interdisciplinary team and in patients' formal treatment plans, and promotes the use of formal referrals to increase visibility and achieve these aims. Giving the music therapist time to get well acquainted with the hospital system was done purposefully, since the music therapist had not worked in a medical context previously. Furthermore, leadership supports the music therapist dedicating time to design and conduct of research, as part of building a solid, research-related music therapy offer.

\section{Limitations}

The findings of this study represent a particular cross section of the implementation process. Since implementation is an ongoing process, there have likely been subsequent changes and developments related to the themes described in this study. For example, in dialogue with the music therapist the leader who participated in this study 
has since changed her mind about the necessity of formal referrals. Focused ethnography enables the study of focused aspects of a field of observation (Knoblauch, 2005), and uses intense data collection across a limited timeframe. Since the observation period in this study was limited to 8 days, supplemented by reflection upon the first author's implemention of praxis on a separate pediatric medical unit, one must appreciate the study's findings in light of this particular context at this particular point in time. Though the findings are not immediately generalizable to all similar settings, they can nonetheless be informative for the various social actors who engage in processes of implementation of music therapy within medical settings.

Using the snowball-sampling method for recruiting interviewees might have led to the blindspot of "what we didn't learn because of who would not talk to us" (Groger, Mayberry \& Straker, 1999, cited in Cohen \& Arieli, 2011, p. 429). It is possible that important perspectives on implementation were missed. Another limitation with this method was that the leader identified the two nurses who functioned as gatekeepers for the music therapist, making it more likely that they had an overall positive attitude towards music therapy.

The interviews were performed, transcribed and analysed by the first author. Since the research was part of a master's thesis we did not have a choice of doing it differently, but some advantages may be that the first author could transcribe hidden gestures and more accurately transcribe the interviewees' tone of voice. However, this double role could result in overlooking important aspects, due to the lack of a fresh perspective on the analysis.

\section{Implications for practice development and future research}

Previous research has demonstrated that implementation of music therapy in a paediatric setting is not easy, and it takes a lot of time and effort on the part of those involved (Aeroe, 2016; Edwards, 2005; Ledger, 2010; Ledger et al., 2013; Mangersnes, 2012). In Norway, music therapy within the paediatric setting is fairly new, which means there are few positions that are well-established and hospital-funded. To facilitate the development of practice, it could be important to research what full-time hospital-funded positions enable that short-term philanthropically-funded positions do not. It would be important to include perspectives directly from children receiving music therapy and their families within future research studies. In addition, it would be valuable to evaluate how patients and families perceive music therapy offerings that are tied to permanent music therapy positions, versus offerings that are related to less stable, philanthropically-funded positions.

The need to develop an integrated and functional system of referrals was a prominent theme in this study. Documentation of music therapy is important so that the processes and outcomes of music therapy are part of the patient's medical journal, and are clearly visible for interdisciplinary staff. Clearly sharing information about music therapy in this way may lead to an increase in the interdisciplinary staff's willingness to make referrals to music therapy.

In Norway, research with a particular focus on music therapy implementation has not yet been conducted in a paediatric setting. This type of research is important to the development of the profession since it helps to critically examine variations in the implementation process. Careful studying of implementation processes helps us identify which factors help or hinder the establishment of music therapy positions, which can provide valuable insight to safeguard the development of music therapy.

\section{Conclusion}

The purpose of this study was to explore healthcare professionals' perspectives on the implementation of music therapy at a children's hospital, an area that has not yet been sufficiently researched in Norway. The results of this study represent a cross section in the ongoing process of implementation at a particular hospital, and demonstrate that experiences among professionals were different, but that it has been relatively straight- 
forward to more systematically integrate music therapy within the treatment offer at this hospital. Adopting organizational theory as a theoretical foundation for the interpretation of data helped identify important aspects of the implementation process. The results of the study are representative of the brief observation and interview period used, and thus it is likely that repeating the study within the same context would bring new knowledge over time. There is a need for more exploration and research on implementation processes within music therapy, both in paediatric settings and in other contexts, in order to support the development of the music therapy profession.

\section{Acknowledgements}

We are grateful to the children's hospital and all the interview participants for making this research possible. A special thank you to the music therapist who invited us to both shadow and interview her, for that we are very grateful. This research received no funding.

\section{Notes}

1. In the Method section, "we" indicates aspects in which both authors engaged, whereas "I" indicates aspects particular to the first author.

2. One of two official forms of written Norwegian, alongside nynorsk.

3. Due to anonymization and confidentiality, the project plan could not be cited in this article.

\section{References}

Aasgaard, T. (2002). Song Creations by Children with Cancer: Process and Meaning. Aalborg: Aalborg Universitet. PhD, Institute of Music and Music Therapy.

Aasgaard, T. (2004). A Pied Piper among White Coats and Infusion Pumps: Community Music Therapy in a Paediatric Hospital Setting. In M. Pavlicevic \& G. Ansdell (Eds.), Community Music Therapy (pp. 147-164). London, England: Jessica Kingsley Publishers.

Aeroe, S. C. B. (2016). Organisering av norsk musikkterapi i pediatri [Organisation of Norwegian music therapy in paediatrics]. Oslo, Norway: Norges Musikkhøgskole. Unpublished Master's Thesis.

Aeroe, S. C. B., \& Aasgaard, T. (2011). Musikkterapeut på en sykehusavdeling for barn : helsefremmende arbeid for både pasient og miljø. Music therapist on a children's hospital unit: Health enhancing work for both patient and milieu. In I. K. Stensaeth \& L. O. Bonde (Eds.), Musikk, helse, identitet (pp. 141-160). Oslo, Norge: NMH-publikasjoner.

Askeland, H. (2013). Hvordan forstå organisasjoner og ledelse organisasjoner?: faglige grunnspørsmål av betydning for organisering og ledelse [How to understand organisations and the management of organisations? Professional issues of importance for organisations and management] (Vols. 2013/10). Diakonhjemmet høgskole. Avdeling for forskning og utvikling. Retrieved from https://brage.bibsys.no/xmlui/bitstream/handle/11250/98637/ haraldom2.pdf? sequence $=1$ \&isAllowed $=y$.

Bradt, J., \& Dileo, C. (2010). Music therapy for end-of-life care. Cochrane Database Systematic Reviews, 2010(1), Cd007169, https://dx.doi.org/10.1002/14651858.CD007169.pub2.

Busch, T., Dehlin, E., \& Vanebo, J. O. (2010). Organisasjon og organisering [Organisation and organising] (6th ed.). Oslo, Norway: Universitetsforlaget.

Cohen, N., \& Arieli, T. (2011). Field research in conflict environments: Methodological challenges and snowball sampling. Journal of Peace Research, 48(4), 423.

Edwards, J. (2005). A reflection on the music therapist's role in developing a program in a children's hospital. Music Therapy Perspectives, 23, 36-44, https://dx.doi.org/10.1093/mtp/ 23.1.36. 
Emerson, R. M., Fretz, R. I., \& Shaw, L. L. (2007). Participant observation and fieldnotes. In P. Atkinson, A. Coffey, S. Delamont, \& J. Lofland (Eds.), Handbook of Ethnography (pp. 352-368). London: SAGE.

Eriksson-Zetterquist, U., Kalling, T., Styhre, A., \& Woll, K. (2014). Organisasjonsteori [Organisational theory]. Oslo, Norway: Cappelen Damm akademisk.

Helsedirektoratet. (2013). Nasjonal faglig retningslinje for utredning, behandling og oppfølging av personer med psykoselidelser [National professional guidelines for assessment, treatment and follow-up of people with psychosis disorders]. Oslo, Norway: Helsedirektoratet Retrieved from https://helsedirektoratet.no/Lists/Publikasjoner/Attachments/326/Nasjonal-fagligretningslinje-for-utredning-behandling-og-oppfolging-av-personer-med-psykoselidelserIS-1957.pdf

Helsedirektoratet. (2016). Nasjonal fagligretningslinje for palliasjon til barn og unge uavhengig diagnose [National professional guidelines for palliative care of children and youth regardless of diagnosis]. Oslo, Norway: Helsedirektoratet Retrieved from https://helsedirektoratet.no/Retningslinjer/Palliasjon til barn og unge.pdf

Helsepersonelloven. (1999). Lov om helsepersonell [Law about health professionals]. Retrievd from https://lovdata.no/dokument/NL/lov/1999-07-02-64 - KAPITTEL_8.

Higginbottom, G. M. A., Rivers, K., \& Story, R. (2014). Health and social care needs of Somali refugees with visual impairment (VIP) living in the United Kingdom. Journal of Transcultural Nursing, 25(2), 192-201, https://dx.doi.org/10.1177/1043659613515715.

Jacobsen, D. I., \& Thorsvik, J. (2013). Hvordan organisasjoner fungerer [How organisations work] (4th ed.). Bergen, Norway: Fagbokforlaget.

Knoblauch, H. (2005). Focused ethnography. Forum Qualitative Sozialforschung / Forum: qualitative Social Research, 6(3), 44, Retrieved from http://www.qualitative-research.net/ index.php/fqs/article/view/20.

Kunnskapsforlaget. (2017). Ordnett.no [wordnett]. http://www.ordnett.no/

Kvale, S., \& Brinkmann, S. (2015). Det kvalitative forskningsintervju [The qualitative research interview] (3rd ed., Anderssen, T. M., \& Rygge, J., Trans.). Oslo, Norway: Gyldendal akademisk.

Ledger, A. (2010). Am I a founder or am I a fraud? Music therapists' experiences of developing services in healthcare organizations. Ireland: University of Limerick. Unpublished doctoral dissertation.

Ledger, A., Edwards, J., \& Morley, M. (2013). A change management perspective on the introduction of music therapy to interprofessional teams. Journal of Health Organization and Management, 27(6), 714-732, https://dx.doi.org/10.1108/JHOM-11-2011-0119.

Malterud, K. (2011). Kvalitative metoder i medisinsk forskning - En innføring [Qualitative methods in medical research - An introduction] (3rd ed.). Oslo, Norway: Universitetsforlaget.

Mangersnes, J. (2012). "Kva er meg, og kva er systemet?" : ei kvalitativ undersøking av musikkterapeutar sine erfaringar $i$ høve til sin rolle og profesjonalitet $i$ arbeid med born på sjukehus "What is me, and what is the system?" : A qualitative exploration of music therapists' experiences in relation to their role and professionalism in work with children in hospital. Bergen, Norway: Grieg Academy, Institute for Music, University of Bergen. Unpublished master's thesis.

Nelson, M. M. (2014). NICU culture of care for infants with neonatal abstinence syndrome: A focused ethnography. Retrieved from ProQuest Dissertations \& Theses Global. Retrieved from https://search-proquest-com.pva.uib.no/docview/1650215085?accountid = 8579

Palmer, J. B., Lane, D., \& Mayo, D. (2015). Surgical music therapy: The significance and implementation of music therapy in the operating arena: Table 1. Music Therapy Perspectives, 35(1), 30-35, https://dx.doi.org/10.1093/mtp/miv036.

Pasient- og brukerrettighetsloven. (1999). Lov om pasient- og brukerrettigheter [Law about patient and user rights]. Retrieved from https://lovdata.no/dokument/NL/lov/ 1999-07-02-63 
Patton, MQ. (1999). Enhancing the quality and credibility of qualitative analysis. HSR: Health Services Research, 34(5), 1189-1208.

Sosial- og helsedirektoratet. (2016). Informasjon om pasienters rettigheter [Information about patients' rights]. Retrieved from http://hbrs.no/filestore/pasientrettigheter2.pdf

Suter, R., Elalem, B., Eisenson, N., White, H., \& Yanamadala, M. (2015). From sleeping to dancing: Implementation of personalized music therapy in residents with dementia. Journal of the American Medical Directors Association, 16(3), B16-B25, https://dx.doi.org/10.1016/ j.jamda.2015.01.034.

Weiner, B. J. (2009). A theory of organizational readiness for change. Implementation Science : IS, 4, 67, https://dx.doi.org/10.1186/1748-5908-4-67. 